\title{
Elas na Ciência: Website com Jogos para Divulgar Personalidades Femininas
}

\author{
Ana Luíza S. Milson ${ }^{1}$, Indra Matsiendra C. D. Ribeiro ${ }^{2}$, Izabela A. Andrade ${ }^{2}$, \\ Julia M. M. Gonçalves ${ }^{2}$, Luísa M. Laboissiere ${ }^{1}$, Marcella D. Ferreira ${ }^{1}$, \\ Daniel H. Dalip ${ }^{2}$, Michele A. Brandão ${ }^{1}$, Mirella M. Moro ${ }^{3}$ \\ ${ }^{1}$ Instituto Federal de Educação, Ciência e Tecnologia de Minas Gerais (IFMG) \\ Ribeirão das Neves, MG - Brasil \\ ${ }^{2}$ Centro Federal de Educação Tecnológica de Minas Gerais (CEFET-MG) \\ Belo Horizonte, MG - Brasil \\ ${ }^{3}$ Universidade Federal de Minas Gerais (UFMG) \\ Belo Horizonte, MG - Brasil \\ milson109asaph@gmail.com, imcdindra@hotmail.com, contatobelaaa@gmail.com, \\ \{julia.mendgoncalves11, luisamarqueslaboissiere, cela.ferreira2009\}@gmail.com, \\ hasan@decom. cefetmg.br,michele.brandao@ifmg.edu.br,mirella@dcc.ufmg.br
}

\begin{abstract}
There is a known gap between the number of men and women in different sectors of society, from academic, market to domestic. Therefore, many studies aim to understand the main factors and solutions for such a scenario. This work contributes to minimize such a gap by developing a website with games that allow promoting female personalities from the Sciences. A usability test was conducted, and the results show that the website and the games are attractive and really capable of teaching about the topic covered.
\end{abstract}

Resumo. Existe uma grande diferença na participação de homens e mulheres em diferentes setores da sociedade, incluindo acadêmico, mercado e doméstico. Por isso, diferentes estudos têm sido desenvolvidos para entender os principais fatores e soluções para tal cenário. Este trabalho contribui para minimizar essa discrepância ao desenvolver um website com jogos que permitem a divulgação de personalidades femininas das Ciências. Um teste de usabilidade foi conduzido, e os resultados mostram que o site e os jogos são atrativos e realmente capazes de ensinar sobre o tema abordado.

\section{Introdução}

Diversos estudos têm analisado e abordado as diferenças significativas entre a quantidade de mulheres e homens matriculados em cursos de graduação. Muitos desses estudos são motivados por estatísticas levantadas por institutos de pesquisa educacionais, por exemplo, o INEP (Instituto Nacional de Estudos e Pesquisas Educacionais Anísio Teixeira), responsável por realizar o Censo da Educação Superior no Brasil. De acordo com tal censo, em 2016, a presença feminina no corpo discente em áreas da ciência tem reduzido nas últimas décadas de $24 \%$ para $14 \%$. Ademais, no censo realizado em $2017^{1}$, na

\footnotetext{
${ }^{1}$ Censo educação superior - 2017: http://portal.mec.gov.br/docman/setembro-2018-pdf/ 97041-apresentac-a-o-censo-superior-u-ltimo/. Acesso 24/04/2020.
} 
listagem dos vinte maiores cursos em número de matrículas, sistemas de informação e ciência da computação são opções para muitos homens, mas não, na mesma proporção, para mulheres. Nesse contexto, Marinho et al. (2019) e Ribeiro et al. (2019) também apresentam estudos que mostram uma participação feminina bastante reduzida em cursos superiores de Bacharelado e Tecnologia.

A crescente democratização do acesso à Internet tornou factível o uso de mídias digitais para o lazer e o aprendizado, uma vez que permitiu o acesso dessas mídias à uma significativa parcela da população pelo barateamento de custos. A Internet permite que o acesso e a troca de informações ocorra de forma bastante rápida [Lisbôa et al. 2009], o que possibilita um maior alcance de pessoas em menos tempo. Essa facilidade de acesso favorece a integração com o meio educacional, que passou a contar com diversos tipos de recursos, como softwares educativos, plataformas de aprendizagem, vídeos e quizzes [Lisbôa et al. 2009]. Essa multiplicidade de ferramentas têm como objetivo aumentar a compreensão sobre o tema, minimizando sua complexidade [Ribeiro 2012].

Todo esse cenário contribuiu para a idealização e motivação do Projeto Bytes \& Elas, cujo objetivo principal é estimular e atrair a participação feminina para as ciências. Há seis instituições de ensino envolvidas, são elas: Centro Federal de Educação Tecnológica de Minas Gerais (CEFET-MG), Colégio Técnico da UFMG (COLTEC), Escola Estadual Governador Milton Campos (também conhecida como Estadual Central), Escola Estadual Maria Luiza Miranda Bastos, Instituto Federal de Minas Gerais (IFMG) campus Ribeirão das Neves e Universidade Federal de Minas Gerais (UFMG). De fato, uma das ações realizadas para alcançar os objetivos deste projeto, foi o desenvolvimento de um website, apresentado neste artigo.

No site desenvolvido, é possível visualizar de forma interativa, informações sobre mulheres cientistas e suas contribuições e, além disso, três jogos, chamados Quem Sou Eu, Ajudando Marie e Jogo da Memória , que abordam as mesmas personalidades femininas. O propósito do site é ser uma fonte de informações e divulgações para facilitar o acesso à informação. Já os jogos, possuem a intenção de fazer as pessoas inteirarem-se, de forma lúdica e didática, gerando interesse e, por consequência, compreensão acerca do tema. É importante salientar que tais jogos foram desenvolvidos, principalmente, para estudantes do ensino médio, com o intuito de mostrar, a partir da história, que há espaço para meninas/mulheres nas ciências.

Neste artigo, apresentamos este projeto além de uma análise do uso do site e dos jogos. Dessa forma, este artigo está organizado conforme segue: a seção 2 discute os trabalhos relacionados; a seção 3 descreve as principais funcionalidades do site; a seção 4 apresenta as principais características dos três jogos; a seção 5 discute os resultados obtidos para a análise de usabilidades do site e jogos; e finalmente, a seção 6 descreve as principais conclusões deste trabalho.

\section{Trabalhos Relacionados}

Muitas iniciativas têm sido realizadas para minimizar essa discrepância e atrair mais mulheres para as ciências, desde projetos (ensino, pesquisa e extensão) até a elaboração de ferramentas. Por exemplo, o projeto Pioneiras da Ciência no Brasil que faz parte do Programa Mulher e Ciência, possui dois grandes principais intuitos: estimular a produção científica e a reflexão acerca das relações de gênero, mulheres e feminismo no país 
e promover a participação das mulheres no campo das ciências e carreiras acadêmicas [Melo and Rodrigues 2018].

Similarmente, outro projeto é o idealizado por Camila Achutti, referência mundial na luta por mulheres na tecnologia e conquistou o prêmio Women of Vision 2015, sendo a primeira estudante latina a receber tal honra ${ }^{2}$. Há também um projeto de lei do senado, PLS 398/18, que influencia a participação das mulheres nas áreas da ciência, tecnologia, engenharia e matemática, idealizado pela senadora Maria do Carmo Alves. Na Ciência e Cultura, apenas $28 \%$ dos pesquisadores do mundo são mulheres ${ }^{3}$, assim, deseja-se criar desde cedo, por meio de abordagens nas disciplinas escolares tradicionais, um ambiente mais livre de estigmas, preconceitos e barreiras, de forma que aquelas estudantes com aptidão e interesse em seguir nas áreas, se sintam encorajadas e seguras para ir em frente, cita Maria do Carmo Alves em seu argumento.

Consoante aos objetivos dessas iniciativas, um jogo de cartas, denominado Computasseia, foi desenvolvido para promover o conhecimento sobre mulheres na História da Computação, ao abordar a imagem e a importância das mulheres que colaboraram para essa área [Santos and da Silva Figueiredo 2016]. Ademais, Santos et al. (2016) propuseram um jogo de tabuleiro, chamado Mulheres na Computação, cuja finalidade é divulgar perfis de mulheres protagonistas na área da computação, além de poder ser utilizado como objeto de ensino.

Os jogos apresentados neste trabalho assemelham-se aos propostos nesses projetos por abordarem personalidades femininas como conteúdo. As principais diferenças são: os conteúdos cobertos são mais amplos, por incluir não apenas mulheres na computação, mas também nas ciências; e os estilos dos jogos, que são de aventura, charada e memória.

\section{O website Elas na Ciência}

O website Elas na Ciência utiliza recursos multimídia, tendo como foco personalidades científicas femininas de destaque nas ciências, além de jogos interativos. Assim, o website é divido em duas partes principais.

Na primeira parte, são disponibilizados jogos com o objetivo de informar os grandes feitos das cientistas. Com isso, pretende-se informar o usuário de uma forma interativa, os grandes feitos dessas cientistas. Tais jogos são detalhados na Seção 4. Além disso, na segunda parte, é apresentado o "sobre Elas" que, a partir de vídeos de curta duração, descreve breves biografias das cientistas, de forma a expor sua história e feitos notáveis. A estruturação é feita com animações simulando um quadro branco, somado a uma narração explicativa e sua transcrição. A adoção desta forma de disseminação de conteúdo busca atingir uma maior quantidade de espectadores, uma vez que o meio audiovisual tem se tornado mais popular entre os espectadores. Segundo Sancho (2001), na atualidade, o indivíduo melhor compreende aquilo que vê do que o que lhe é contado.

Em síntese, almeja-se alcançar um público mais extenso, além de permitir maior captação e entendimento do conteúdo. Ademais, é importante salientar que este tipo de conteúdo é compatível com as necessidades de indivíduos portadores de diferentes

\footnotetext{
${ }^{2}$ Camila Achutti: https://mulheresnacomputacao.com/author/cachutti/. Acesso 24/04/2020.

${ }^{3}$ UNESCO: Mulheres são apenas $28 \%$ das pesquisadoras em todo o mundo: https://nacoesunidas . org/unesco-mulheres-sao-apenas-28-das-pesquisadoras-em-todo-o-mundo/ Acesso 24/04/2020
} 


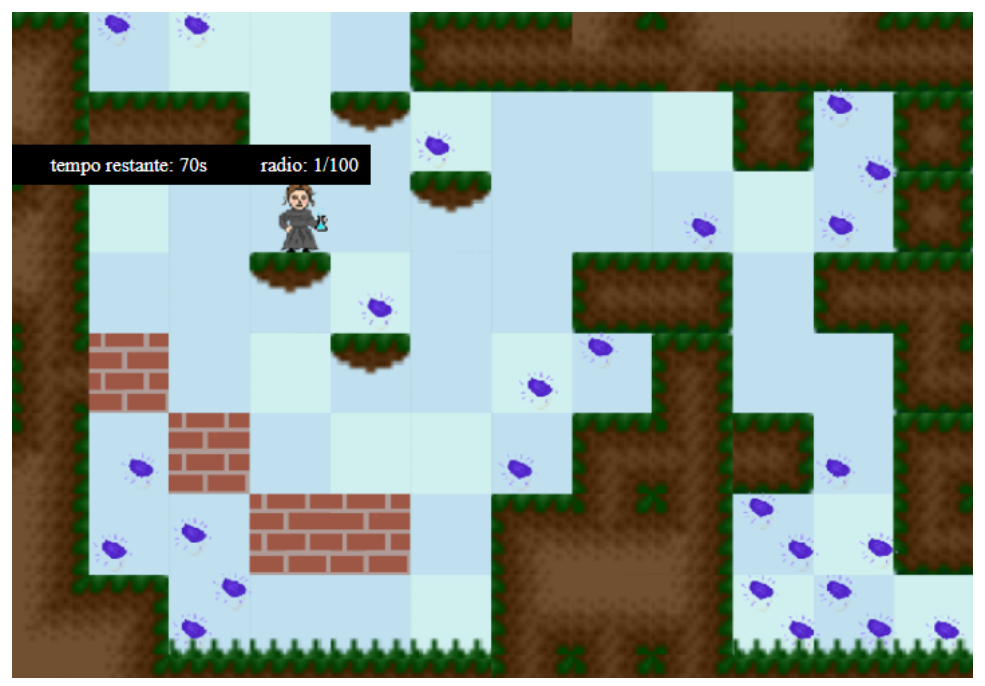

Figura 1. Ambiente de Jogo "Ajudando Marie".

deficiências. O meio auditivo permite que deficientes visuais compreendam o conteúdo, assim como a transcrição somada às imagens possibilita o entendimento daqueles com capacidade auditiva comprometida.

\section{Jogos e a Divulgação de Informação}

Ao longo do desenvolvimento do meio técnico-científico-informacional, diversos dispositivos e atividades passaram a ser acessíveis à generalidade da população. No contexto atual, jogos eletrônicos se tornaram um passatempo comum, em especial para jovens e crianças. Entretanto, essa forma de entretenimento veio a se tornar uma espécie de vício para muitos que dedicam uma parcela superior de tempo para jogos do que outras praxes, como deveres de casa ou diversões ao ar livre [Kirriemuir and Mcfarlane 2004].

De fato, pesquisadores e educadores buscam formas de não cessar a conexão existente entre alunos e jogos, mas usar do meio digital de forma favorável ao aprendizado, devido aos benefícios dos mesmos. Os jogos são capazes de motivar os seus jogadores, principalmente, por três motivos: fantasia, desafios e curiosidade [Malone 1981]. Os três jogos desenvolvidos neste trabalho buscam incorporar esses aspectos. Ademais, os jogos foram projetados utilizando as linguagens HTML, CSS e JavaScript, sendo esta última responsável pelas principais funcionalidades.

\subsection{Ajudando Marie}

O mini-jogo "Ajudando Marie" tem como personagem Marie Curie, uma das cientistas mais conhecidas por suas contribuições no ramo da radioatividade. O objetivo é ensinar sobre a história dessa importante cientista para que esta sirva de inspiração.

Metodologia. Este jogo se enquadra na categoria aventura, e como tal, todo o ambiente foi desenvolvido de forma a estimular os jogadores, com a presença de sons, música de fundo e mudança de cenários. O jogador tem como missão coletar todas as pedras de Rádio no limite de tempo definido, como é apresentado na Figura 1. A missão do jogo foi pensada com base na história da cientista, assim, a personagem usada é um pixelart ${ }^{4}$

\footnotetext{
${ }^{4}$ Pixelart: https://www.pixilart.com/
} 


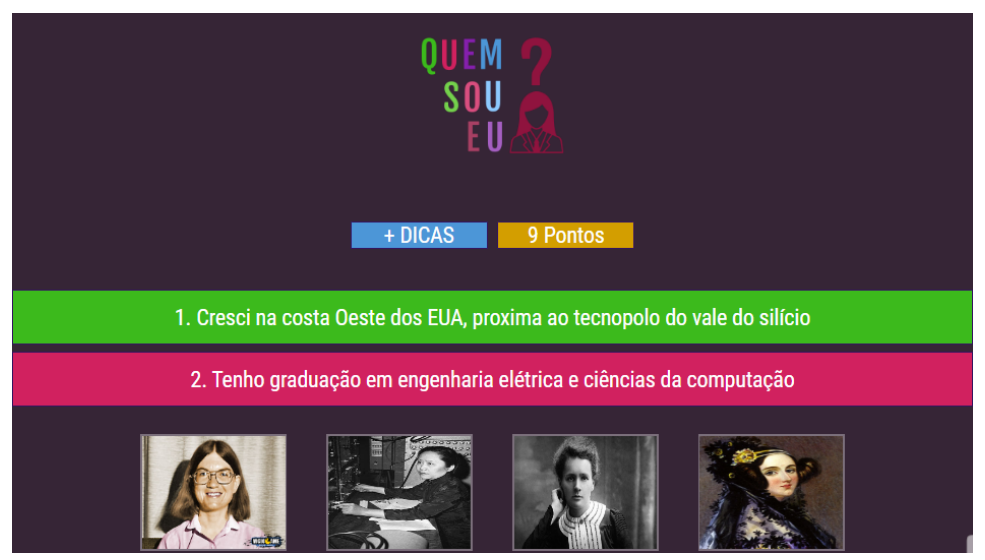

Figura 2. Ambiente de Jogo "Quem sou eu?”.

da Marie Curie e o item coletado é um dos elementos químicos descobertos por ela. Ademais, o jogo é de fácil entendimento, pois já na introdução são apresentadas, juntamente com a história de Marie, instruções sobre como jogar. Desse modo, o jogador melhora sua atenção a detalhes, reações rápidas e aprende sobre o tema, dentre tantos outros benefícios já comprovados para jogos desse tipo.

Limitações e desafios. Atrair o interesse de jovens por jogos educativos se mostra um desafio, principalmente, em um mercado com tantos jogos voltados unicamente para diversão que recebem um investimento muito maior. O jogo "Ajudando Marie" também passa por essa dificuldade, pois apresenta apenas um nível, sendo assim, pode ser considerado fácil pelos jogadores e não atrair a atenção por muito tempo, se comparado aos jogos mais populares atualmente.

\subsection{Quem Sou Eu}

O mini-jogo "Quem Sou Eu" tem como objetivo principal que os jogadores desenvolvam maior conhecimento sobre mulheres que apresentaram vultosa importância na área de ciências. Essa aprendizagem busca colocar o usuário em uma posição de decisão, de forma a adquirir conhecimentos a partir da tentativa e erro. Isso é algo tradicional em jogos, segundo a pesquisa de Mitchell e Savill-Smith (2004).

Metodologia. O ambiente desenvolvido apresenta imagens de quatro figuras femininas de relevância e seus nomes, além de uma pista, informação, sobre a mulher de quem se fala, conforme mostra a Figura 2. O jogador deverá, a partir dos dados apresentados e de seus conhecimentos, inferir a personalidade. O meio divertido, com imagens e alternativas de escolha foi elaborado intencionalmente buscando uma apreensão também visual das individualidades em estudo, além de apresentar ao usuário outras personagens, distintas daquela em análise. A atividade procura incentivar a curiosidade do utilizador sobre a temática. No contexto de erro, são prestados esclarecimentos sobre a mulher escolhida, de forma a acrescer um conhecimento sobre ela; outrossim, a resposta não é apontada e não há penalização, de forma a estimular o jogador a permanecer empenhando-se. Um ambiente seguro, destituído de ameaças e dotado de um retorno instantâneo estimula um aprendizado por descoberta, uma vez que o usuário pode se sentir mais encorajado à exploração [Mitchell and Savill-Smith 2004]. O aprendizado por descoberta, por sua 


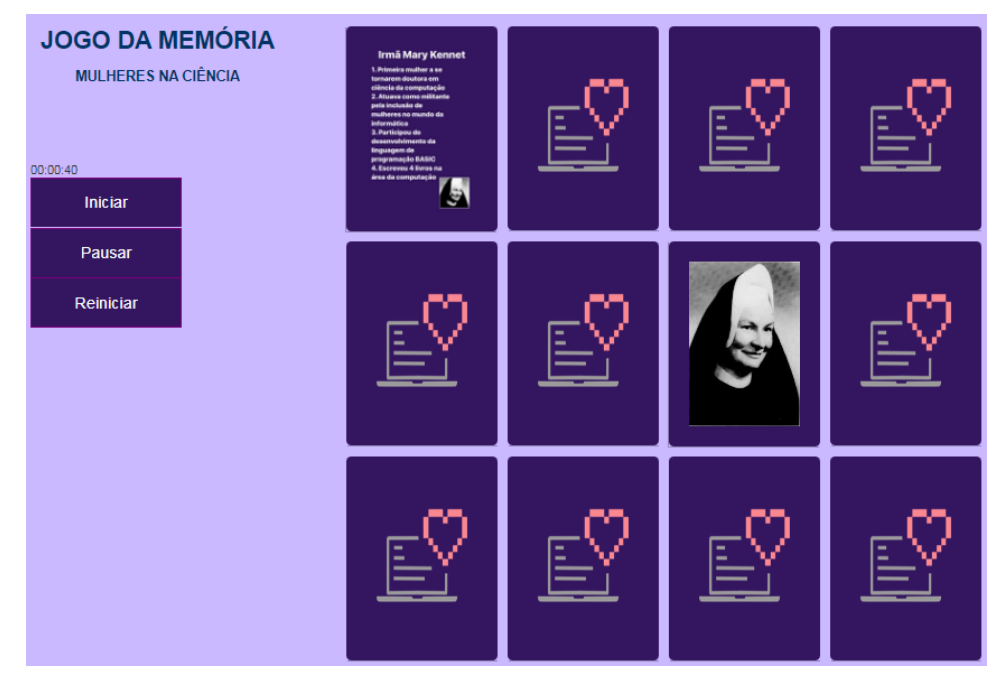

Figura 3. Ambiente do Jogo da Memória.

vez, se refere àquele que desenvolve capacidades de explorar, experimentar, colaborar [Becta 2003]. Assim, os dados apresentados nas dicas, assim como nas notificações de erro auxiliam na apreensão de conhecimentos sobre a figura.

Limitações e desafios. Os jogos educacionais, apesar de amplamente utilizados, apresentam aspectos negativos que desestimulam seu uso [Kirriemuir and Mcfarlane 2004]. Isso também acontece com o jogo "Quem sou eu?". Dentre esses aspectos, podemos citar a simplicidade da ferramenta se comparada com jogos comuns, a presença de uma tarefa repetitiva e simples, além da concentração de aprendizado em uma única habilidade.

\subsection{Jogo da Memória}

O mini-jogo da memória tem como objetivo passar aos jogadores conhecimentos sobre seis mulheres importantes para a computação. Tendo em vista que jogos desse tipo são de conhecimento mundial e jogados até por crianças, se torna de fácil entendimento o conteúdo, já que primordialmente, o jogador não terá que focar em como jogar e sim nos conteúdos contidos.

Metodologia. O jogo foi desenvolvido de forma simples, conforme mostra a Figura 3, contém 12 cartas, sendo 6 delas imagem de mulheres importantes para a computação e as outras 6, informações correspondentes a essas mulheres. Isso difere da tradicional forma desse tipo de jogo, o qual, geralmente, contém duas fotos iguais. Isso foi desenvolvido com o intuito de levar um aprendizado maior, pois o jogador terá que ler as informações contidas na carta e relacioná-la à foto encontrada na outra carta. Entretanto, pensando em um melhor aprendizado, foi adicionado à carta, uma pequena foto da cientista - o que em algumas cartas são até diferentes das imagens correspondentes - para que, dessa forma, o jogador não fique perdido e saiba relacionar uma carta à outra corretamente.

Limitações e desafios. O maior desafio dos jogos educacionais digitais, como o em questão, é alcançar a aprendizagem, portanto, a falta de experiência e disciplina pode acarretar em um deficit nesta. É preciso atenção, o jogador deve ler as cartas que contém informações e não só olhar a foto para relacionar. A falta de interesse neste tipo jogo na 
Tabela 1. Teste de usabilidade baseado em [Nielsen 1994].

\begin{tabular}{|c|c|}
\hline Questionário & Atende? \\
\hline $\begin{array}{l}\text { Facilidade de aprendizado - se refere ao tempo e esforço necessários para } \\
\text { que os usuários aprendam a utilizar uma determinada porção do sistema } \\
\text { com bom nível de competência e desempenho }\end{array}$ & $\begin{array}{l}75 \% \text { - total } \\
25 \% \text { - parcial }\end{array}$ \\
\hline $\begin{array}{l}\text { Facilidade de uso - está relacionado não apenas com o esforço cognitivo } \\
\text { para interagir com o sistema, mas também com a facilidade de completar } \\
\text { a interação sem cometer erros durante este processo }\end{array}$ & $\begin{array}{l}65 \% \text { - total } \\
32,5 \% \text { - parcial } \\
2,5 \% \text { - não }\end{array}$ \\
\hline $\begin{array}{l}\text { Flexível - considera o quanto um sistema é capaz de acomodar caminhos } \\
\text { distintos para se atingir um mesmo objetivo, apoiando assim as preferências } \\
\text { e modo de trabalho individuais dos usuários }\end{array}$ & $\begin{array}{l}57,5 \% \text { - total } \\
40 \% \text { - parcial } \\
2,5 \% \text { - não aplica }\end{array}$ \\
\hline $\begin{array}{l}\text { Produtivo - analisa se o sistema consegue fazer bem aquilo a que se destina, } \\
\text { e se o usuário completa suas tarefas de forma rápida e eficaz }\end{array}$ & $\begin{array}{l}67,5 \% \text { - total } \\
32,5 \% \text { - parcial }\end{array}$ \\
\hline $\begin{array}{l}\text { Satisfatório - enfatiza a avaliação subjetiva do sistema feita pelo usuário, } \\
\text { incluindo suas preferências pessoais e emoções (positivas ou negativas) } \\
\text { que possam surgir durante a interação }\end{array}$ & $\begin{array}{l}57.5 \% \text { - total } \\
40 \% \text { - parcial } \\
2,5 \% \text { - não }\end{array}$ \\
\hline
\end{tabular}

faixa-etária entre jovens e adultos se encontra como uma limitação, também, pelo fato do público alvo serem crianças.

\section{Resultados do Teste de Usabilidade}

Com o objetivo de avaliar a usabilidade do site e dos jogos pelo usuário, foi realizado um teste de usabilidade. Tal teste foi aplicado via Formulários Google que foi divulgado para pessoas de diferentes faixas etárias, mas principalmente, que cursam o ensino médio técnico em escolas públicas. Para esse questionário, foram formuladas perguntas baseadas no trabalho de [Nielsen 1994] que apresenta princípios de usabilidade: (1) facilidade de aprendizado; (2) facilidade de uso; (3) flexível; (4) produtivo; e (5) satisfatório. Tais princípios foram transformados em perguntas no qual o usuário respondia se a aplicação atende ou não a este principio, conforme apresentado na Tabela 1.

No total, foram obtidas quarenta respostas, cujo perfil caracteriza-se como $61,5 \%$ do gênero feminino, $33,3 \%$ do gênero masculino, $2,6 \%$ se identifica com outro gênero e 2,6\% preferiram não declarar. Além disso, $71,8 \%$ do público tem de 15 a 17 anos, $7,7 \%$ tem de 18 a 21 anos, outros 7,7\% tem de 22 a 30 anos e outra porção de 7,7\% está na faixa dos 31 a 50 anos. Apenas 5,1\% tem dos 12 aos 14 anos. A escolaridade foi outro ponto abordado, em que foram recebidas $76,9 \%$ das respostas sendo de pessoas com o ensino médio ainda em andamento, $7,7 \%$ com a graduação em andamento, $5,1 \%$ com a graduação concluída, 2,6\% com a pós graduação em andamento, 7,7\% tendo a pós graduação concluída. Quando perguntadas se já fizeram algum curso relacionado à computação, 63,2\% responderam que sim e 36,8\% responderam que não. A partir desses dados, observa-se que o perfil predominante dos respondentes é de mulheres que tem entre 15 e 17 anos, com o ensino médio em andamento e que já fizeram ou fazem cursos relacionados à computação. A justificativa para tal perfil predominante pode ser o foco do site, que é mulheres na ciência. Isso mostra a necessidade de ampliar a divulgação para que mais pessoas, de perfis distintos, possam acessar o website.

Considerando tais perfis de respondentes, a Tabela 1 mostra as perguntas do ques- 
tionário com respectivas respostas. Quatro opções de múltipla escolha (atende completamente, atende parcialmente, não atende e não se aplica) foram dadas para que fosse escolhida a que mais se encaixasse com a experiência do usuário. Observa-se que para todos os aspectos abordados (facilidade de aprendizado, facilidade de uso, flexível, produtivo e satisfatório), a maioria dos respondentes indicam que o site e os jogos atendem completamente ou parcialmente.

Especificamente, para o aspecto facilidade de aprendizado, $25 \%$ pensam que o site e os jogos atendem apenas parcialmente. Já em relação ao aspecto facilidade de uso, $32,5 \%$ dizem que atendem parcialmente, e ainda 2,5\% acreditam que a facilidade de uso não esteja sendo alcançada pelo sistema. Quanto à flexibilidade, $40 \%$ dos usuários acreditam que o sistema tem um desempenho parcialmente flexível, e 2,5\% dos entrevistados acreditam que é um aspecto que não pode ser avaliado. Finalmente, para os aspectos produtivo e satisfatório, 32,5\% e 40\% dizem que são atendidos parcialmente, respectivamente. Ainda para o aspecto satisfatório, 2,5\% dizem que o site e os jogos não atendem.

Dessa forma, é necessário que sejam feitas revisões no site e nos jogos para encontrar as dificuldades enfrentadas pelos usuários. Para fazer mudanças e melhorias, é preciso observar com mais atenção as reclamações recorrentes, já que as que ocorrem poucas vezes podem ser apenas preferências pessoais de alguns usuários. Por isso, na última seção do formulário, foram solicitadas observações, em questões abertas para os usuários descreverem pontos fortes e os pontos fracos de cada um dos jogos. A partir dessas respostas, podemos analisar quais foram as dificuldades e insatisfações.

Ajudando Marie. Considerando os pontos fortes, foram obtidas vinte e sete respostas, enquanto no campo de pontos fracos tivemos vinte e oito. Na opinião dos usuários, os pontos fortes do jogo são a presença da figura feminina, o caráter educativo, o design, a música agradável e, principalmente, o fato de ser divertido, desafiador e intuitivo, o que acaba prendendo a atenção de quem joga. Além disso, a movimentação da personagem e os efeitos visuais bem trabalhados foram elogiados, assim como o texto colocado no início sobre a vida de Marie Curie, que foi descrito por muitos como algo interessante e que contribui para o conhecimento. Como pontos fracos, foram citados principalmente o tempo curto que é dado para a realização das tarefas do jogo, assim como a ausência de um fim ou um objetivo claro a ser cumprido e também reclamações sobre não ser possível jogar em dispositivos móveis.

Quem sou eu?. Foram obtidas trinta respostas sobre os pontos fortes e vinte e sete respostas sobre os pontos fracos. No campo de pontos fortes, vários usuários relataram a importância que o jogo teve para o aprendizado sobre as mulheres na ciência, assim como incentivou-os a estudar mais sobre as mesmas, já que não as conheciam. Além de ressaltar o caráter educativo do jogo, muitos destacaram que a aplicação é desafiadora, divertida e intuitiva e também houve elogios em relação ao design, uso das imagens e escolha das cores. No campo dos pontos fracos, foram apresentadas muitas respostas distintas, sendo que as mais frequentes diziam que deveria ser indicado um estudo prévio sobre as mulheres antes de começar o jogo, além de reclamações sobre uma falha no servidor que impediu de terminar o jogo ou que não foi possível jogar pelo celular e algumas respostas diziam que às questões às vezes tem respostas muito fáceis. Além disso, outras respostas diziam que há biografias muito parecidas e grandes para as mulheres, que não há um 
indicador de progresso ou um objetivo final no jogo e também havia pessoas insatisfeitas com o design e a escolha das cores.

Jogo da Memória. No campo de pontos fortes foram obtidas trinta e uma respostas e no de pontos fracos, trinta. Em muitas respostas sobre os pontos fortes, destaca-se que o jogo é desafiador, divertido e criativo, além de ser fácil de jogar, por ser um clássico. Também foi observado pelos usuários que o fato de relacionar a imagem das mulheres com os feitos delas traz conhecimento e aprendizado de forma lúdica, além de trabalhar a memória. Alguns disseram que o tempo do jogo também é positivo, por não ser muito curto nem muito longo, e algumas pessoas também elogiaram o design e a paleta de cores. Os pontos fracos apontados foram principalmente o fato de não ser possível ler as informações escritas nas cartas pela letra ser muito pequena e os textos serem grandes, além de muitos que não conseguiram entender o jogo de primeira, já que esperavam que fosse para relacionar duas cartas iguais, e não uma com foto e outra com texto. Além disso, o próprio usuário ter que apertar um botão para iniciar e finalizar o jogo foi considerado um ponto negativo, pois para muitos seria mais intuitivo se o tempo começasse a contar quando é virada a primeira carta e o cronômetro parasse quando o último par é acertado. Houve, além das queixas principais, algumas respostas que relataram que o design é muito simplista e que as imagens estão distorcidas, assim como reclamações sobre não haver um aviso quando o tempo termina, sendo que a pessoa pode continuar jogando mesmo já tendo perdido.

Finalmente, as alunas relataram que o projeto permitiu "...sentir que cresci, em sentido profissional, aprendendo com novos conteúdos e desafios, e o mais importante, pude desenvolver um pouco do meu emocional. Percebi em mim mais do que apenas defeitos, mas qualidades que antes tinha dificuldade de enxergar; me auxiliou na compreensão de que eu sou sim capaz, que estou no lugar certo e principalmente, a notar e me incomodar que muitas meninas ainda não conheceram o que pode vir a ser seu lugar também.”, “...compreender melhor diversos requisitos que me faziam não gostar da área da informática. Com isso, percebi que tudo não passava de preconceitos que existiam implícitos em mim e o projeto me ajudou a quebrá-los.", "...perceber que gosto muito de informática, e quero realmente seguir nessa área, aprendi mais sobre diversos conteúdos ao programar e percebi o quanto a causa pela qual lutamos é importante e, quando ele terminar, sempre que eu tiver oportunidade vou incentivar as mulheres que conheço a não desistirem da ciência, pois elas podem ser aquilo que quiserem.”, “...conhecer mais sobre a área da computação no sentido profissional, além de ter quebrado alguns preconceitos que eu tinha com relação à informática. Além disso, aprendi a trabalhar em equipe e também conheci as mulheres que revolucionaram a ciência, que agora levo como inspiração.", e "...mais conhecimentos sobre as mulheres que fizeram história na ciência, além de me mostrar que existem várias formas didáticas de aprender, como jogando.”.

\section{Conclusão}

Neste artigo, foi apresentado um website com três jogos, que objetivam divulgar personalidades femininas na computação e nas ciências, principalmente, para estudantes do ensino médio. Tal website é um dos produtos do Projeto Bytes \& Elas e foi desenvolvido por alunas do ensino médio do técnico integrado. Além do projeto e seus produtos beneficiarem à comunidade, conforme apresentado nos resultados, também contribuiu para a formação das alunas que desenvolveram o projeto. Finalmente, como trabalhos futu- 
ros, planeja-se considerar os pontos fracos levantados pelos usuários e melhorar os jogos, analisar a acessibilidade dos website e jogos, avaliar a aprendizagem gerada pelos jogos, e ampliar a divulgação do website.

Agradecimentos. Trabalho financiado pelo Projeto CNPq Bytes \& Elas, 442265/2018-2.

\section{Referências}

Becta, X. (2003). Computer games in education project report. British Educational Communications and Technology Agency Archive.

Kirriemuir, J. and Mcfarlane, A. (2004). Literature Review in Games and Learning. A NESTA Futurelab Research report - report 8.

Lisbôa, E., Junior, J., and Coutinho, C. (2009). Contributo do vídeo na educação online. In Anais do X Congresso Internacional Galego-Português de Psicopedagogia, Braga, Portugal.

Malone, T. W. (1981). Toward a theory of intrinsically motivating instruction. Cognitive science, 5(4):333-369.

Marinho, G., Fagundes, S., and Aguilar, C. (2019). Análise da participação feminina nos cursos técnicos e de graduação da área de informática da rede federal de educação tecnológica e do cefet/rj campus nova friburgo. In Anais do XIII Women in Information Technology, pages 21-30, Belém, Brasil.

Melo, H. P. d. and Rodrigues, L. (2018). Pioneiras da ciência no brasil: uma história contada doze anos depois. Ciência e Cultura, 70(3):41-47.

Mitchell, A. and Savill-Smith, C. (2004). The use of computer and video games for learning. A review of the literature.

Nielsen, J. (1994). Usability inspection methods. In Conference companion on Human factors in computing systems, pages 413-414.

Ribeiro, L., Barbosa, G., Silva, I., Coutinho, F., and Santos, N. (2019). Um panorama da atuação da mulher na computação. In Anais do XIII Women in Information Technology, pages 1-10, Belém, Brasil.

Ribeiro, N. (2012). Multimédia e tecnologias interativas. FCA-Editora Informática Lisboa.

Sancho, J. L. V. (2001). La infografía: técnicas, análisis y usos periodísticos, volume 9. Universitat de València.

Santos, J. C. O. and da Silva Figueiredo, K. (2016). Computasseia: Um jogo para o ensino de história da computação. In Anais do XXIV Workshop sobre Educação em Computação, pages 31-40. SBC.

Santos, P. d., Lopes, G. M., de Oliveira, A. B., dos Santos, P. R., and de Mello, A. V. (2016). Jogo mulheres na computação: Uma forma de divulgar o protagonismo feminino. Anais do Salão Internacional de Ensino, Pesquisa e Extensão, 8(3). 